\title{
“They Are Married to kunqu”-Cultural Studies Inspired by a Chinese Traditional Theatre
}

\author{
CHEN Lin \\ International Research Group “InterArt Studies”, Freie Universität Berlin, Berlin, Germany
}

\begin{abstract}
In recent decades, a new type of cultural upsurge surrounding kunqu ${ }^{1}$ has arisen in Chinese language sphere, though respectively due to different reasons in Mainland China, Hong Kong, Taiwan and other Chinese diaspora. Against the global trend of culture heritage nationalization context, via the new media platform, the performative staging of individual emotions and reverie in the market society ${ }^{2}$, the longings to redeem various alienation in a vertical modernity ${ }^{3}$, as well as the yearnings for emotional balance in a burgeoning feministic modernity, all integrate with each other and together generate a restless transforming memory for kunqu. Just like a misty veil, this complex, contentious, contradictory and long-lasting collective memory-making process blurs kunqu's appearance, expands its layers, and ultimately generates a cultural myth. With detailed case studies this paper aims to reflect upon the deep reasons for the kunqu myth and to probe the transformative powers of a performative space in enabling remembrance and/or forgetting.
\end{abstract}

Keywords: kunqu, performative space, classical cultural upsurge, multiple modernities, cultural memory

\section{Prologue}

The year 2012 is the "Chinese Culture Year" in Germany. The organizers put forward the claim that authentic traditional Chinese culture would be presented. With regards to this claim the Jiangsu kunqu Ensemble was invited to perform three authentic "Zhe-zi Xi " $/$ One Act kunqu" as part of the opening ceremony in February, and Luzia Braun, the "Stellvertretende Leiterin des ZDF-Kulturmagzins Aspekte" was invited as the moderator. The performance lasted two nights in Konzerthaus Berlin.

\footnotetext{
CHEN Lin, Ph.D. Candidate, International Research Group “InterArt Studies”, Freie Universität Berlin.

${ }^{1}$ kunqu is a traditional Chinese theatre form born in Kunshan area, southeast China. According to the monographs of Lu E-ting and $\mathrm{Hu} \mathrm{Ji}$, kunqu achieved its mature form as performing art around middle Ming Dynasty, went through its glory era to Qianlong period in the Qing Dynasty, and once fascinated almost three-fourths China. However, since the end of Qing Dynasty, kunqu suffered a dramatic decline, even on the edge of lost. kunqu used to be named as Kunqiang, Kundiao, Kunju etc., nowadays in order to introduce kunqu to the international stage it is also translated as Kun Opera. In 2001, kunqu was acknowledged as UNESCO's masterpiece of “Oral and Intangible Heritage of Humanity”.

2 As elaborated by Michael Sandel, the term market society differs from market economy by implying that capitalist market economics influences not just the exchange of goods and services in a society, but also directly impacts and helps shape the personal attitudes, lifestyles, and political views of its people.

3 To learn more about Multiple Modernities please refer to S. N. Eisenstadt, Daedalus, Vol. 129, No. 1, Multiple Modernities 2000, pp. 1-29.

${ }^{4}$ Zhe-zi Xi is the mature form of kunqu as a performance art. The noun "Zhe-zi” cannot be successfully rendered into English, and in this paper, Zhe-zi Xi is translated as One Act kunqu, which was selected from Full Acts kunqu.
} 
Generally speaking it was a nice experience, the live accompaniment impressed the audience favorably, yet the performance was a little different from my former kunqu experience in China. They saved the expense to transport the essential stage properties, namely the one desk and two chairs to Berlin. Without them, two female performers seemed clumsy in showing some beautiful stylized gestures from the Peony Pavilion.

After the performance an intense interview process was held. Towards the end, the moderator Luzia Braun proposed her master-stroke to Ke Jun, director of the Jiangsu kunqu ensemble, "Herr Ke, would you tell us the most obvious difference between kunqu and Peking Opera?” "Well”, Ke Jun answered determinately, "Peking Opera is entertainment, but kunqu is culture.”

Ke Jun's answer shocked the audience, especially those who love the Peking Opera. Why did Ke Jun make such an assertion? What led to his boldness? Since kunqu and Peking Opera are both beloved, the social status of professional performers were equally humble in imperial China as well as equally eminent nowadays, and not to mention the One Act kunqu "fleeing in the night" he staged that night is also in Peking Opera's repertoire, why did he show such an arrogance? What kind of information did he actually want to convey? Does such opinion belong to himself, his ensemble, the kunqu performance field, or much wider, even involving the whole Chinese language sphere? Does this claim merely convey a new flavor in the performance art field, or does it actually indicate some new ideological, political, or institutional tendencies? To elaborate on these questions, we may first let some internal cases into our scope.

In winter 2003, actress Liang Guyin from the Shanghai kunqu ensemble and researcher Zhang Peiheng from the Fudan University were invited to hold a conversation talking about kunqu, primarily about the Peony Pavilion. This conversation was titled as No Such Thing Anymore-Die for One Dream, Resurrect for Another. The title was alluding to the plot of the Peony Pavilion. Notably Zhang Peiheng was no theatre scientist, but renowned as an authority in Chinese classical philology.

Appreciating the beauty, primarily the beautiful lyrics, of Peony Pavilion and kunqu, they talked about the enthusiasm around kunqu in recent years and together emphasized kunqu's elegant drama texts and its tie-up with the elite culture ${ }^{5}$ in the imperial China as well as in the Republic of China, especially with the Confucian scholars in the Ming and Qing Dynasties.

Yet they were no longer of the same mind when talking about how to protect and preserve kunqu. kunqu was proclaimed by the UNESCO as "masterpiece of oral and intangible heritage" in 2001. Zhang held his opinion firmly that kunqu belongs to the bygone days, and its doomed destiny is the museum. According to him, to inherit the traditional kunqu performance style should be the main task for us if we want to protect kunqu. On the contrary, the prominent actress Liang Guyin explained that she agrees with the government's policy and insists on a path to innovate kunqu.

Afterward when discussing about the charm of kunqu, Liang Guyin described a remarkable phenomenon in Taiwan: "ca. 90 percent of the kunqu audience are young people, the majority are the female, and many of them studied kunqu for more than ten years. Besides, those females devoted themselves solely to kunqu. They have no time for personal or family life as if they are married to kunqu.” Liang Guyin described such an

\footnotetext{
${ }^{5}$ Elite culture is a concept in contrast with folk culture, which resembles the contrast between great tradition and little tradition proposed by Robert Redfield.
} 
phenomenon willingly, for she is one of the most popular Mainland China kunqu teachers in Taiwan ${ }^{6}$. Yet Zhang Peiheng considered such enthusiasm of kunqu, a theatre form, as crossing the border.

This case delivered us much important information about kunqu, such as its revival in recent years. Meanwhile some questions are naturally and simultaneously formed in our brain, when we try to cope with the information delivered.

China is widely accepted as a modern society with its own attributes, which could be considered as one version of multiple modernities ${ }^{7}$. Yet China still shares some basic features with other modernities, such as modernity means a rigid dualistic cosmos perspective turns into a performative one. As Eisenstadt summarizes, "the emergence of a range of possible modernities takes place when what had been seen as an unchanging cosmos ceases to be taken for granted”8. Against such context, it seems indeed hard to persist in the idea that some performance style should or could be preserved exactly the same as it was, moreover every performance already has the performative attribute in itself. Not to mention that during the New Culture Movement \& Cultural Revolution many traditional arts were seriously damaged. It is impossible to restore the traditional kunqu exactly as the one that existed even hundred years ago.

Then why does Zhang ignore the performative attributes of performance art and the trend of our time? Why does he disapprove of the government's innovation policy as well as with the performers? Does Zhang represent the opinion of some non-governmental intellectuals as well as some sub-cultural groups? Furthermore what are the reasons for kunqu's present revival in Mainland China and Taiwan? Does the revival of kunqu take place simultaneously with the revival of other traditional arts? And most of all, how to explain the Taiwanese female's subtle feelings and border-crossing enthusiasm for kunqu?

\section{General Analysis}

We may set about our analysis of these questions first with a brief study of kunqu's developing history and its unique characteristics, to see if some of these questions could be settled.

A distinct feature of most Chinese traditional theatre is that for quite a long time there was no fixed drama text for them. For ages the basic texts for staging have been passed down from masters to pupils orally. Moreover, the daily life language, such as the language for the vernacular novels, is good enough for the drama text, and therefore the performers are also capable of improvising text on the stage. On the contrary, since its birth in the Ming Dynasty, kunqu got used to the situation that the text must be created by literati with refined poetic language, and the drama text must be crowded with a large number of literary quotations, which is beyond the comprehension capacity of uneducated audience. As Zhang Peiheng also admitted, the capability to write such a text is beyond the literati and intellectuals of our age, owing to the irresistible modernization process since the beginning of the last century.

\footnotetext{
${ }^{6}$ Since 1990s kunqu performers from Shanghai kunqu ensemble as well as nonprofit kunqu scholars (those exclusively take interest in the melody and the complicated articulation methods) were invited to Taiwan to be the teachers. Before that, the stage in Taiwan only witnessed the charm of Peking Opera and other local theatres.

7 To learn more about Multiple Modernities please refer to S. N. Eisenstadt, Daedalus, Vol. 129, No. 1, Multiple Modernities 2000, pp. 1-29.

${ }^{8}$ S. N. Eisenstadt, Daedalus, Vol. 129, No. 1, Multiple Modernities 2000, p. 4.
} 
According to the monographs of Lu E-ting ${ }^{9}$ and $\mathrm{Hu} \mathrm{Ji}^{10}$, kunqu achieved its mature form as performing art around the middle of the Ming Dynasty (1368-1644), went through its golden times to Qianlong period (1711-1799) in the Qing Dynasty (1644-1912), and for decades fascinated almost three-fourths China. Besides, the phonological rules as well as the articulation methods of kunqu are the most complicated in all Chinese traditional theatres. The process to train a qualified kunqu performer was also amazing, and many ancient monographs in the Qing Dynasty were dedicated to this.

However, since the end of the Qing Dynasty kunqu suffered a dramatic decline. Around late Qing Dynasty the folk audiences as well as the royal court no longer favor any elegant kunqu performance on the stage. They booed the performers off the stage, for the new tendency was towards something more unrestrained, with faster rhythm, and more expressive, such as the new born Peking Opera. Since 1990s this anti-classical tendency in the late Qing Dynasty as well as in the Republic of China era is researched by leading Harvard researcher Leo Lee, who identifies this tendency as the initial stage of Chinese own modernity ${ }^{11}$. No matter what kind of deep reasons for the new flavor were, the kunqu performers were booed off the stage. Wars and revolutions in the early 20th century gave kunqu the final fatal blow. It was on the edge of being lost before the foundation of PRC.

Solid facts prove that in the Ming Dynasty (1368-1644), unlike most folk theatre, kunqu enjoyed a close tie-up with the Confucian scholars, the elite culture. Even in the middle Qing Dynasty (1644-1912) the Emperor Qian Long still issued edicts proclaiming kunqu's “Great Elegance” status compared with the predecessor of Jingju and other folk theatre forms.

Furthermore, though declined since late Qing Dynasty, kunqu is widely acknowledged as the mother of all the Chinese folk theatre which are still active nowadays. In history it has indeed nurtured most of the Chinese folk theatre we know today, such as the much beloved Sichuan Opera, Peking Opera, Shaoxing Opera etc.

According to the brief introduction of kunqu's characteristics above, one conclusion can be drawn that kunqu indeed deserves our respect and protection. This should be one reason for Zhang Peiheng's concern and his conservative opinion against the government's policy. Zhang finds it unwise to renovate this living fossil, moreover he can't identify the innovation with the protection.

As many researchers demonstrate, kunqu's beauty and charm are established on its characteristics and its history. Not to mention the other attributes, such as the lyrics of the Peony Pavilion, would fascinate the reader. Though declined and even was on the edge of death in the 1950s, in recent decades more and more people in Mainland China as well as in Taiwan obtain fair pleasure and consolation appreciating the texts of kunqu, learning its melodies, its phonological rules, its articulation methods and the traditional stylized performance.

However, this is still not convincing enough to explain the enthusiasm surrounding kunqu or the female Taiwanese's subtle emotions to it. There must be something else, some other crucial factors against the ideological as well as the political context. Let's first focus on Taiwan.

\footnotetext{
${ }^{9}$ Lu E-ting, Zhao Jing-shen (Eds.), Study of kunqu’s Staging History, Shanghai Wenyi Press, 1981, pp. 14-44.

${ }^{10} \mathrm{Hu}$ Ji, Liu Zhizhong, The Developing History of Kunju, Chinese Theatre Press, 1989, pp. 1-36.

11 Leo Lee, The Pursuit of Modernity, Taibei Maitian Press, 1996.
} 


\section{kunqu in a Burgeoning Feministic Modernity}

On 13th October 2011 the BBC journalist Cindy Sui made a special topic report keeping traditional Chinese culture alive ${ }^{12}$. In this article, she wrote that "Taiwanese people are proud of the way they have preserved traditional Chinese culture.” Nowadays Taiwan is worldwide accepted as symbol for loving and preserving traditional culture. Yet this is actually a relatively new phenomenon, which is around since the 1970s.

As Xu Zhi-yuan, Chen Jun-rong, Lin Yao-de, Wang An-qi and many other researchers elaborated ${ }^{13}$, due to the stimulation of the decision by the United Nations that Taiwan was no longer accepted as an independent nation since 1971, the cultural fashion in Taiwan apparently changed. Since the 1970s and the 1980s, numerous Taiwanese people no longer idolize the Western culture. In contrast, for the first time, they turned to traditional Chinese culture as well as the native and primitive culture, determined to find a new spirit of home and the roots for Taiwan. The local party DPP (Democratic Progressive Party, Taiwan), sloganeering as representing the value of local culture and local identity, made great progress during this time. In the art's field, many famous art groups dealing with classical Chinese dance, music and theatres, came into being in this new trend, such as Yunmen Wuji Dance Association and Lanling Jufang Theatre Workshop. The state theatre Peking Opera are also loved by young people since this time period.

Apparently the above-mentioned classical culture revivals as well as the political context all contribute to the later upsurge around kunqu. Without this background it is impossible to understand the enthusiasm of kunqu in Taiwan since the 1990s. But why didn't this upsurge happen until 1990s, why not in the 1970s or the 1980s as the Peking Opera did? The answer is simple: because before the 1990s, Taiwanese stage hardly witnessed a theatrical art named kunqu.

President Chiang Kai-shek did not manage to take kunqu performers to Taiwan in the $1949^{14}$. The reason was explained above, namely at that time, kunqu was on the edge of being lost. In a hurry there was not enough time for President Chiang Kai-shek to search for the kunqu performers lost in the vast folk. Though some old scholars who flied to Taiwan were able to sing many melodies from kunqu, they were no professional performers.

The relationship across the straits was rather serious for decades. Up to the 1990s, Mainland China and Taiwan finally began to communicate with each other, above all in the cultural sphere. In the year 1991 kunqu was for the first time brought to Taiwan by the Shanghai kunqu ensemble.

Appreciating the kunqu performance, many Taiwanese's dust sealed memories about the lost world suddenly became vivid, especially for those who were born in Mainland China and once experienced the intoxicated decadence in the Republic of China. For them, a lost sentimental home came back. Taiwanese renowned author Bai Xianyong (son of the warlord Bai Chongxi in the Republic of China era) names himself as voluntary labor for kunqu. He visited Suzhou (a city full of cultural memory near Shanghai) kunqu ensemble

\footnotetext{
12 See from http://www.bbc.co.uk/news/world-radio-and-tv-15153707.

13 Xu Zhi-yuan, 2012; Chen Jun-rong, Lin Yao-de, 1990; Wang An-qi, 1998, pp. 10-11.

14 The Republic of China, founded in 1911 after the overthrow of the Qing Dynasty, ruled the Chinese mainland until 1949. In 1945, the ROC acquired Taiwan from the Empire of Japan following World War II. In the 1946-1949 phase of the Chinese Civil War, the Communist Party defeated the nationalist Kuomintang in Mainland China and established the People's Republic of China in Beijing on 1 October 1949, while the Kuomintang relocated the ROC government to Taipei.
} 
many times in recent years and together with the kunqu artists staged the modernized full acts Peony Pavilion, namely the Youth Peony Pavilion. They performed in Taiwan, Hong Kong, Mainland China, Singapore, the USA, Australia and so on. This is a big advance for the kunqu upsurge in the Chinese language sphere. Not to mention the alliance of eminent directors such as Peter Sellars and Chen Shizheng, although their Peony Pavilions are forbidden in Mainland China. A high tide of kunqu in all Chinese language spheres, especially in Taiwan and Mainland China emerged. News, videos, performances, melodies, teaching videos, articles, accesses to learn or appreciate classical kunqu, the foundation of new non-governmental \& non-profit kunqu groups, blogs to share experiences \& feelings and so on, are all available on the new interactive media platform. Young kunqu lovers become the backbone in this trend. Here are some facts to show kunqu's popularity in Taiwan. Merely two kunqu performances visited Taiwan in the year 1990, yet nowadays there are numerous professional as well as amateur performances. In 1949 there were just two non-governmental kunqu lovers' groups, i.e. the Shuimo Quji and Pengying Quji, established by the old scholars followed President Chiang Kai-shek to Taiwan, yet nowadays dozens of new kunqu lovers' groups have been founded. Moreover, from 2011 the National Taiwan University sets regular courses as well as lectures for kunqu. Bai Xianyong is invited as the leading lecturer ${ }^{15}$. For more information about the popularity of kunqu in Taiwan and a scrutiny of this history from 1990 to 2012 please refer to the essay published by the Taiwanese kunqu researcher Fly ${ }^{16}$. Nevertheless it is still difficult to understand the Taiwanese females' border-crossing love to kunqu, because such behavior is quite different from other kunqu lovers in other Chinese diaspora.

In order to study the effect of Bai Xianyong's Youth Peony Pavilion I surfed a long time on the Internet, reading reports as well as reviews written by the audience. Quite typical is an article written by an American Chinese who described her personal experiences after watching the staging of Bai Xianyong's Youth Peony Pavilion in New York. She wrote, "(I and my husband) were watching the performance, suddenly the sweet feelings to each other that lost in our marriage years ago emerged in our heart." kunqu helped her marriage. Owing to this, this female might set up the journey to learn more about kunqu, use the internet platform to get more information and to communicate with the others, watch more kunqu performances, even pay visit to kunqu lovers' groups as well as kunqu scholars, and constantly achieve pleasure by appreciating and learning kunqu, just like me and many other young people. Yet she would in no case give up her marriage for kunqu. Moreover kunqu might just be the very reason that encouraged a marriage, not only in the Republic of China, even today. Owing to the round performances in Hongkong, the USA and so on, the heroine of the Youth Peony Pavilion got married to a successful wealthy Hong Kong businessman. One of my friends in Shanghai gave up her major in environmental engineering and studies theatre science in the Shanghai Theatre Academy since she fell in love with kunqu, meanwhile she got married with her husband who also appreciates the beauty of kunqu and other classical art forms. The love of kunqu should be no obstacle to a secular life. Then how to explain the border-crossing love of kunqu from those Taiwanese females? What is the ultimate reason for this?

Virtually, to be single is a trend amongst the highly educated Taiwanese females nowadays as reported by

\footnotetext{
15 See from http://ocw.aca.ntu.edu.tw/ntu-ocw/index.php/ocw/cou/099S128/1, http://www.dfdaily.com/html/150/2011/3/9/577539.shtml, and http://www.trend.org/event/Kunqu_lecture/index.html. 16 Fly, 2012.
} 
the Wall Street Journal ${ }^{17}$. Different from other modern societies, Taiwan used to be a strict patriarchal society. According to studies by feminism research institute of the Taiwan University ${ }^{18}$, though widely accepted as modern society, the female status in Taiwan was for quite a long time restrained even like in a feudal society.

The first feminist magazine as well as institution in Taiwan was founded in 1982. Only after June 1998 it became finally legal for women to keep their original family name after getting married. And meanwhile, law against domestic violence was finally passed by the Legislative Yuan in Taiwan. Before that, abuse and violence within marriage were beyond the reach of law. All of those progresses mainly owe to the fight of Taiwanese females, especially the highly educated ones such as Li Yuanzhen and Peng Wanru. Sadly Peng Wanru was raped and killed brutally in 1996 in Kaohsiung ${ }^{19}$. Not only the feminists but all the women in Taiwan were shocked and launched the 1221 March $^{20}$ with deep grieve for her death. The 1221 March directly appealed for the “Nv Xing Ye Xing Quan (security guarantee for the women to travel alone in the night)”.

No wander nowadays many feminists in Taiwan are so cautious about marriage, they identify it as some kind of surrender to the patriarchal power since it is hard to find an appropriate partner. Against this context the reason for the border-crossing love and indulgence of kunqu from the Taiwanese females eventually becomes clear. Not as Liang Guyin asserted, that those females are married to kunqu owning to its beauty, quite the other way, the indulgence of kunqu accompanied their single way. Those young females are not single because of the love of kunqu. On the contrary, the love of kunqu becomes consolation for their idle time besides work. Namely the indulgence of kunqu turns out to be the emotional balance for some of the Taiwanese females who choose to be single. Naturally there are also many other emotional balances for the female in Taiwan, such as uptown nightclubs and successful career as reported by the Wall Street Journal as well as Sina news ${ }^{21}$.

As analyzed above, the upsurge surrounding kunqu in Taiwan mainly owes to three causes. Firstly, the determination to search for a new spirit of home and to create new national identity from the classical Chinese culture as well as native culture since the 1970s, when Taiwan was expelled from the UN. Secondly, the creative work of some minorities who indulged themselves in the profound complex of the Republic of China, such as Bai Xianyong. For those individuals, kunqu no longer presents itself as a pure, delicate, and integrated performance art, but provides a performative space, where individuals could project their own longings, emotions and desires. Thanks to the platform provided by the new media, especially web 2.0, those individual imagination contribute prominently to a collective memory-making process. Thirdly, this upsurge is also in virtue of the burgeoning feminism championed in Taiwan.

Then how about Mainland China, Hong Kong and other diaspora? Do they enjoy the same reason or

\footnotetext{
17 See from http://cn.wsj.com/gb/20100416/trv085301.asp?source=channel.

18 The Three Waves of Feminist Criticism in Taiwan, Tzuhsiu Chiu (Graduate Institute of Taiwanese Literature National Chung Cheng University), 2005.

19 In November 1996, Peng disappeared in Kaohsiung, Taiwan; the public last saw her board a yellow Ford Telstar taxi after a DPP meeting the night prior to a DPP convention. She was discovered raped and murdered outside of an abandoned warehouse in Kaohsiung County (now part of Kaohsiung City); her body had more than 30 stab wounds. Despite extensive investigation, the police were unable to solve the crime. Peng's murder produced an outcry against a perceived lack of protection given to women in Taiwan. Peng's proposed quota for one fourth of the seats of the elected seats to be reserved for women passed during the November 30, 1996 DPP National Congress meeting.

20 The march was from 19.30 December 21st to 06.00 December 22nd, and was named as 1221 March. Peng Wei-jing and Liang Yu-fang, United Daily News, 22nd. Dec. 1996.

${ }^{21}$ See from http://edu.sina.com.cn/en/2010-04-19/154855492.shtml.
} 
something else? This paper will analyze the kunqu revival in Mainland China as an example.

\section{kunqu in a Market Society and Vertical Modernity}

Resembling Taiwan, the revival of classical culture, in other words the nationalization of the past and the creation of cultural heritage as Stephen Owen (Borrowed Stones, 2006) demonstrated, serves the Chinese government as well as various agencies as one of the ideological possibilities to coin a neo national identity ${ }^{22}$. Speeches full of classical literary quotations delivered by Premier Wen Jiabao on different occasions owe much to this consideration. Yet the other two factors for kunqu's upsurge in Taiwan don’t suit Mainland China very much.

On 10th March 2007 Hong Kong Ming Daily News (Mingbao) published one compelling report with harsh language and anxiety: "A group of scholars appealed to Chairman Hu Jintao and Premier Wen Jiabao to save kunqu—kunqu is cultural heritage, not a culture industry”. ${ }^{23}$ In fact this report was an adaptation of a petition written together a year ago by scholars such as Gu Zhaoshen, Luo Di, Zhang Lizhen, Lei Jingxuan, Liu Chuhua, Zheng Peikai and Gu Tiehua, some of whom are noted theatrologists and others are renowned Qu You (literally means kunqu adherents). The report argued that, "The government's policy is totally wrong to modernize kunqu and try to make commercial profit out of it". ${ }^{24}$ It is stated that "classical kunqu is doomed to decline with Chinese classical culture and kunqu's ending is museum. kunqu's modernization only disqualifies it as a cultural heritage.” This report was immediately shared on several Internet forums including the Bulletin Board System of Beijing University (pkucn) ${ }^{25}$, BBS of Nanjing University (nju) ${ }^{26}$, and Xici Lane ${ }^{27}$, and aroused fierce discussions not only by theatre scholars, kunqu Adherents ( $Q u$ You), but also by young kunqu fans. Seven days later, on the 17th of March 2007 Hong Kong Dagong Daily News (Dagong Bao) published an article supporting Hong Kong Ming Daily News's point of view under the name of "Scholars appealing to stop the commercialization of kunqu".

From the case above we can infer that three main forces are to be observed in the kunqu's upsurge in China. Namely the central government and some kunqu performers; the local government together with all kinds of commercial groups; and the non-governmental forces, which include some intellectuals, $Q u$ You (kunqu adherents) and kunqu lovers. Besides these three main forces some audience as well as some scholars are also participating the discussion. In the kunqu upsurge these three main forces with respective goals are fiercely incompatible with each other.

As a performing art, kunqu has the performative attribute in itself. Besides, because of the New Culture Movement, the Great Proletarian Cultural Revolution and the irresistible modernization since the beginning of the last century many traditional arts were seriously damaged, it is impossible to restore the traditional kunqu exactly the same way as they existed even only one hundred years ago, then why are those scholars thoroughly disapprove of the innovation policy of the central government? What on earth lead to their uneasiness? Scholars

22 See also Li Ling, 12th. Oct. 2011.

23 Hong Kong Ming Daily News (Mingbao) on the 10th of March 2007. Shanghai library. Newspapers and Magazines archives. Reported by journalist Situ Haoxin.

${ }^{24}$ Ibid.

25 See from http://www.pkucn.com/redirect.php?tid=197668\&goto=lastpost.

${ }^{26}$ See from http://bbs.sjtu.edu.cn/bbscon?board=ChinaPlay\&file=M.1176964114.A.

27 See from http://www.xici.net/d93340004.htm. 
such as Gu Duhuang even argue that China should preserve the "authenticity of traditional kunqu", even though kunqu as a performance art enjoyed a de facto performative developing history and it is fruitless insisting on the so called authenticity, which is per se a problematic concept.

Moreover, the third force do not only oppose the renovation project of the government, but also the stagings of Peony Pavilion directed by Chen Shizheng, Peter Sellars or Shanghai kunqu ensemble. To sum up, they are disapproving of any innovation or modernization of kunqu, no matter whether it is splendid art or just kitsch on the stage. I studied the performance analysis of three Peony Pavilions by Judith Zeitlin, and according to her record, the staging directed by Peter Sellars is gorgeous. Yet for political reasons it is forbidden by the Chinese government, and for some other reasons it is refused by the kunqu lovers in China. What are the reasons? Could that be the same reasons which urged those scholars that wrote the petition? Could that also be linked with the very reasons for kunqu's revival in nowadays China?

According to my field study 2011 in Beijing, Shanghai and Suzhou, as well as my personal experiences, long before the government, mass media and commercial groups paid special attention to kunqu, some individuals have endeavored to preserve the singing part of kunqu, even in the Cultural Revolution. kunqu and other classical forms of fine art became their sole company during that gloomy age ${ }^{28}$. Most of them are intellectuals and noted kunqu adherents, some of whom are respected as kunqu scholars ${ }^{29}$. Quite different and much more complicated than the way kunqu actors and ensembles following nowadays, those kunqu scholars believe that the articulation methods to sing kunqu they preserved are based upon ancient phonology. Besides, kunqu performances in their memories are also quite different from the modern way, because some gestures, properties and staging methods of traditional kunqu Zhe-zi Xi were arbitrarily changed by some governmental officers and some actors since the 1980s and are quite hard to restore.

Those individuals contributed a lot in the proclamation of kunqu by the UNESCO as masterpiece of oral and intangible heritage in 2001. After that, two other forces, namely the central government as well as all kinds of commercial groups including the local governments began to investigate in kunqu and together with the mass media advanced the upsurge. As Marty Roth summarized, the compulsion to seize the past through memory can be seen in several forms, and two of them hit China, namely the "dedication by the mass media to reconstructing and re-staging history" ${ }^{30}$ as well as "the development of modern tourism, heritage sites and industries". 31

The kunqu scholars have learned what they believe to be the authentic kunqu from their teachers and are ready to teach the newcomers, the young kunqu lovers. This is a non-governmental way to preserve Chinese traditional culture. My teacher Liu Xuan-tu was one of those celebrated kunqu scholars. She was descendant of a notable family and worked as an art editor since 1949 in Shanghai. Virtually the ebb and flow of kunqu in mass media are indifferent for them, yet they could not stand the destructive commercial utilization of kunqu by the local governments as well as by the professional kunqu ensembles for commercial profit, such as endless commercial performances which was called kunqu yet were delivered in a kitsch, haphazard way. Moreover,

${ }^{28}$ Please refer to Zhang Yihe's memoirs The Last Nobles, Oxford Press, 2004.

${ }^{29}$ This group has been paying much attention to by the American sinologists nowadays.

${ }^{30}$ Marty Roth, The Cultures of Memory: Memory Culture, Memory Crisis and the Age of Amnesia. Academica Press 2011, p. xii.

${ }^{31}$ Ibid. 
because of all the traumatic memories of the decade, i.e. during the Cultural Revolution, they even could not stand any innovation of kunqu, though some of the innovations such as new concept kunqu experiments directed by Peter Sellars and Danny Yung achieved high aesthetic value.

Because kunqu was once their sole spiritual company, a passive way to resist all kinds of alienation, they could not bear any change of it. Besides them, kunqu resembling the classical culture in an artistic way is highly valued by more and more ordinary people in a vertical modern China, as a way to search for a new spirit home.

For most European countries, modernization was achieved alongside the enlightenment process. In other words, modernization guarantees the transformation of one society from vertical feudal structure to a horizontal one. Yet Chinese modernity is a little different. Up to present, it is still kind of a vertical society. All aspects of the society, including economy, education, health care, political rights, even environment and sustenance, presented to us the brutal reality, i.e. the vertical modernity. Celebrated scholar Wang Hui delivered such an speech at the Falling Walls Conference 2011 in Berlin, i.e. Breaking the Wall of Social Divide. How Political, Economic and Social Critique identifies the Five Faces of Equality ${ }^{32}$. Besides explaining his solution for the social problems, he demonstrated the fact that, modern China is still an unjust vertical society. This means that besides the alienation of the market society, individuals in Mainland China also have to deal with the fatal pressure produced by this particular vertical structure.

Resembling the females in Taiwan, individuals in Mainland China also need some emotional balance to project individual desires and reverie, to redeem various alienation and the pressure in this vertical modernity. To resist the alienation of the market society, to protest kunqu against the commodification trend that tries to make profit from the intangible heritage, and to establish some new spiritual homeland in this lost modernity, all these wishes finally together generate the non-cooperative attitude toward the government's modernization plan of kunqu. These are the deep reasons for the petition to preserve the imagined authentic kunqu. The search for the spirit home is projected on Kunqu. Though their efforts might finally still be utilized by the mass media to reconstruct and re-stag history, which finally serves the market society.

To sum up, against the global trend of culture heritage nationalization context, via the new media platform, the performative staging of individual emotions and reverie in the market society ${ }^{33}$, the longings to redeem various alienation in a vertical modernity ${ }^{34}$, as well as the yearnings for emotional balance in a burgeoning feministic modernity, all integrate with each other and together generate a restless transforming memory for kunqu. Just like a misty veil, this complex, contentious, contradictory and long-lasting collective memory-making process blurs kunqu's appearance, expands its layers, and ultimately generates a cultural myth.

Just as Astrid Erll ${ }^{35}$ analyzes, collective memory making process is "the interplay of present and past in socio-cultural context”. It is incontestable that the upsurge surrounding kunqu and other classical culture

\footnotetext{
32 See from http://falling-walls.com/lectures/wang-hui-2/.

33 As elaborated by Michael Sandel, the term market society differs from market economy by implying that capitalist market economics influences not just the exchange of goods and services in a society, but also directly impacts and helps shape the personal attitudes, lifestyles, and political views of its people.

34 To learn more about Multiple Modernities please refer to S. N. Eisenstadt, Daedalus, Vol. 129, No. 1, Multiple Modernities 2000, pp. 1-29.

35 Astrid Erll, Ansgar Nuenning (Eds.), A Companion to Cultural Memory Studies, De Gruyter, 2010, p. 2.
} 
meanwhile serves the individuals as a subconscious way of licking the wounds that are inevitable.

\title{
Epilogue
}

Like Montaigne and Roth, I write on memory because I have so little of myself. The imagined daily life of China, embodiment of cultural memory, which is ready to be called up on the screen, is far from my bygone personal experience. Maybe exactly as Nora charges, memory is constantly on our lips because it no longer exists $^{36}$, or even as Huyssens analyzes, contemporary China is "locked between remembering everything and forgetting what is most important”37. Yet what is important? This question is hovering over my heart for years. This article is an endeavor to blow off some mist around the upsurge surrounding Chinese classical culture as well as kunqu, meanwhile to expel the strange feelings brought by the realization of the modern alienation.

\section{Glossary}

\author{
Bai, Chong-xi 白崇禧 \\ Bai, Xian-yong 白先勇 \\ Chen, Yi-ru 陳怡如 \\ $\mathrm{Hu}, \mathrm{Ji}$ 胡忌 \\ kunqu 昆曲 \\ Kunju 昆劇 \\ Ke, Jun 柯軍 \\ Lee, Leo 李歐梵 \\ Liu, Zhi-zhong 劉致中 \\ Lu, E-ting 陸萼庭 \\ Ming Dynasty 明朝 1368-1644 \\ Peng, Wan-ru 彭婉如 \\ Qing Dynasty 清朝 1644-1911 \\ The Last Nobles 最後的貴族 \\ Wang, An-qi 王安祈 \\ Wang, Hui 汪暉 \\ $\mathrm{Xu}, \mathrm{Zhi}$-yuan 許知遠 \\ Zhao, Jing-shen 趙景深 \\ Zhang, Yi-he 章詒和
}

\section{References}

Chen, J. R., \& Lin, Y. D. (1990). 世纪末偏航: 八0年代台湾文学论 (At the turn of the century: Taiwan literary theory in the 80s).

Taipei: ShiBao Wenhua Publishing Press.

Eisenstadt, S. N. (2000). Multiple modernities. Daedalus, 129(1), 4.

Erll, A., \& Nuenning, A. (Eds.). (2010). A companion to cultural memory studies. Berlin: De Gruyter.

FLY. (2012). 崑曲經驗在台灣 (kunqu in Taiwan). 中國崑曲藝術 (Chinese kunqu Art).

\footnotetext{
${ }^{36}$ Pierre Nora, Realms of Memory: Rethinking the French Past. NY: Columbia UP, 1996, Volume 1.

37 Andreas Huyssen, Present and Pasts: Urban Palimpsets and the Politics of Memory, Stanford UP, 2003, p. 17.
} 
Hu, J., \& Liu, Z. Z. (1989). The developing history of Kunju. Beijing: Chinese Theatre Press.

Huyssen, A. (2003). Present and pasts: Urban palimpsets and the politics of memory. Palo Alto: Stanford University Press.

Lee, L. (1996). The pursuit of modernity. Taipei: Taibei Maitian Press.

LI, L. (Li Ling, 12th. Oct. 2011). 环球同此凉热 (Under the Same Sky).

Lu, E. T., \& Zhao, J. S. (Eds.). (1981). Study of kunqu's staging history. Shanghai: Shanghai Wenyi Press.

Nora, P. (1996). Realms of memory: Rethinking the French past (Vol. 1). NY: Columbia University Press.

Peng, W. J., \& Liang, Y. F. (1996). 女權火照夜路數千人上街頭, 火姖哨音為女性衝破黑夜 (Fire of feminism lightens the night streets and thousands of people march, Torch whistle breaks through the darkness for women). United Daily News, 22nd. Dec.

Roth, M. (2011). The cultures of memory: memory culture, memory crisis and the age of amnesia. Palo Alto: Academica Press.

Situ, H. (10th, March, 2007). A group of scholars appealed to Chairman Hu Jintao and Premier Wen Jiabao to save kunqu—kunqu is cultural heritage, not a culture industry. Hong Kong Ming Daily News (Mingbao).

Wang, A. Q. (1998). 戲裡乾坤大: 平劇世界 (A Whole New World of Peiking Opera). Taipei: Hanguang Wenhua Publishing Press.

Xu, Z. Y. (2012). 八 十年代 (The Eighties). Hong Kong: Financial Times China. 